\title{
Una característica producción cerámica pintada del Período Ibérico pleno en el sur de la Meseta
}

\author{
Germán Esteban Borrajo
}

\section{Resumen}

El objetivo de estas lineas es el estudio de un singular conjunto de cerámica pintada característica del periodo ibérico pleno del sur de la Meseta. Dicho conjunto constituye un elemento arqueológico valioso para la indagación en diversos aspectos de la Oretania prerromana.

\section{Summary}

The subject of these lines is the study of a singular group of paint pottery characteristic of the Iberican Period in the south of the spanish Meseta. This group contains an important archeologic element about the interpretation of differents aspects of the iberic Oretania

\section{INTRODUCCIÓN}

El desarrollo de la cultura ibérica en gran parte del sector sur de la Meseta es una faceta bastante desconocida de la Arqueología Peninsular. A pesar de que, aún en la actualidad, el volumen de la investigación de esta etapa de la Protohistoria en la zona geográfica que corresponde aproximadamente a la actual provincia de Ciudad Real no es ni mucho menos grande ni cuantitativa ni cualitativamente (Esteban-Hevia, 1996, 537), es ya posible abordar con ciertas garantías la caracterización de diversos aspectos referentes al poblamiento y, sobre todo, a la cultura material, especialmente durante el transcurso del periodo ibérico pleno.

Precisamente, entre los restos de la cultura material que mejor caracterizan este momento en dicho territorio, queremos destacar en esta ocasión una singular producción de cerámicas a torno pintadas que desarrollan una decoración bícroma que combina anchas bandas anaranjadas o, en menos ocasiones, de diversas tonalidades rojizas, marrones amarillentas o grisaceas, con otras bandas estrechas así como distintos motivos geométricos en color rojo vinoso. A veces, las cerámicas con decoración pintada de estas características se decoraron también mediante impresiones de estampillas. Los tipos cerámicos formales sobre los que se llevó a cabo este característico modo decorativo son, por supuesto, los habituales del periodo ibérico pleno.

El grueso de hallazgos arqueológicos de este tipo de cerámica a torno pintada (fig. 1) se encuentra localizado en la zona central y oriental de la provincia de Ciudad Real, en torno a un eje principal formado por el río Jabalón, en un espacio cultural ibérico individualizado hace ya años por Martín Almagro Gorbea, la denominada Área de Valdepeñas (Almagro Gorbea, 1976-78). Se han hallado sin embargo diversas manifestaciones del tipo en lugares periféricos a dicha área, e incluso en puntos bastante alejados de la misma; ello, unido a la importancia que esta clase cerámica alcanzó entre las demás manifestaciones materiales de los principales centros del área de Valdepeñas durante el periodo ibérico pleno, justifica plenamente su análisis individualizado.

HALLAZGOS DE CERÁMICA A TORNO PINTADA BÍCROMA DE TIPO VALDEPEÑAS

Posiblemente, el principal conjunto de cerámica a torno pintada bícroma del tipo al que venimos refiriéndonos documentado hasta la actualidad es el procedente del yacimiento del Cerro de las Cabezas (Valdepeñas, Ciudad Real), 


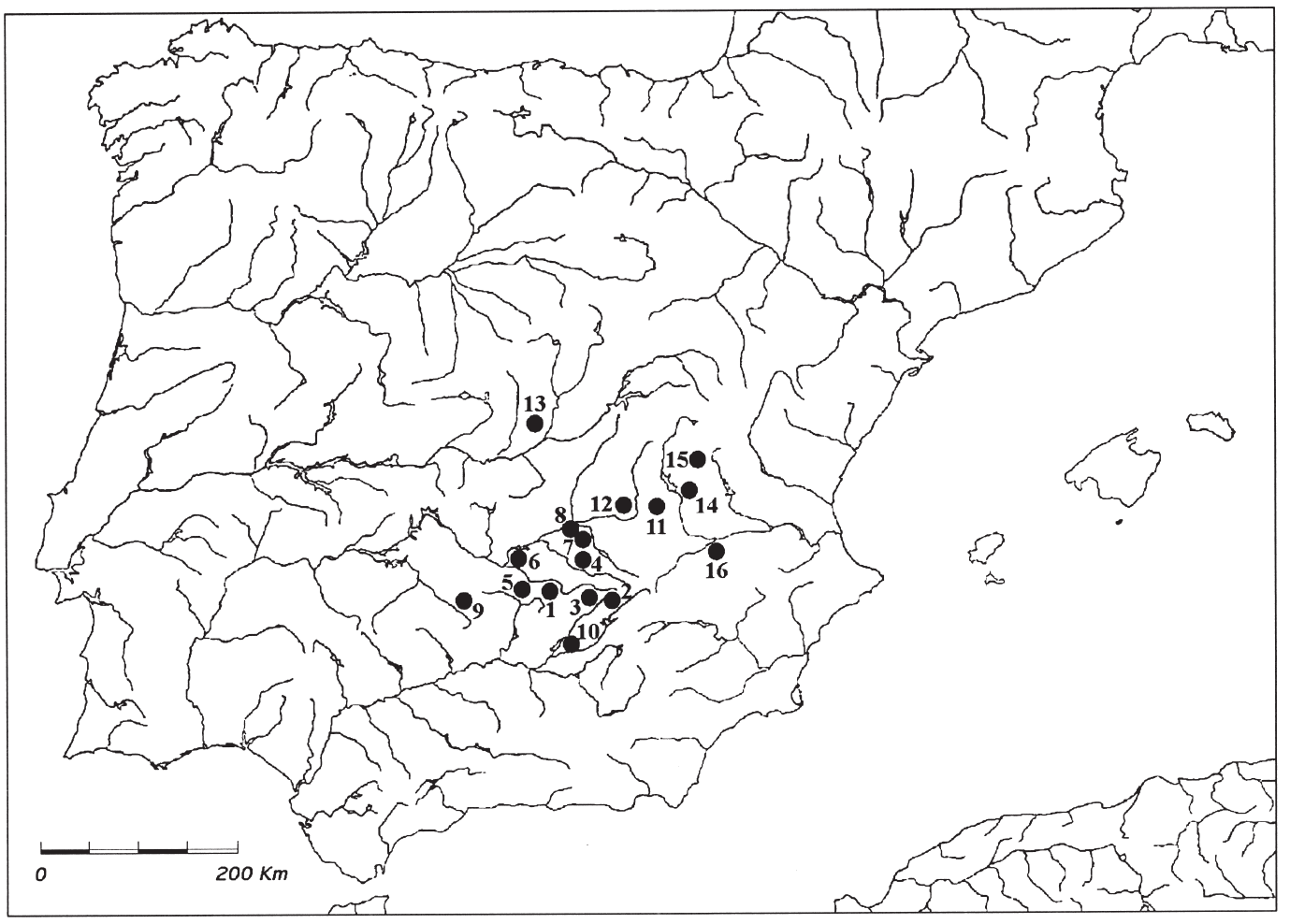

Fig. 1. Yacimientos con cerámica a torno pintada tipo Valdepeñas: 1. Cerro de las Cabezas (Valdepeñas, Ciudad Real). 2. Almedina (Ciudad Real). 3. La Pizarrilla (Cózar, Ciudad Real). 4. Villar o Molino de los Moros (San Carlos del Valle, Ciudad Real). 5. Cerro Domínguez (Granátula de Calatrava, Ciudad Real). 6. Alarcos (Ciudad Real). 7. Motilla de los Palacios (Almagro, Ciudad Real). 8. Motilla de la Isla de las Cañas (Daimiel, Ciudad Real). 9. La Bienvenida (Almodóvar del Campo, Ciudad Real). 10. Cástulo (Linares, Jaén). 11. Cerro de las Nieves (Pedro Muñoz, Ciudad Real). 12. Palomar del Pintado (Villafranca de los Caballeros, Toledo). 13. El Cerrón (Illescas, Toledo). 14. Olmedilla de Alarcón (Cuenca). 15. Reillo (Cuenca). 16. El Amarejo (Bonete, Albacete).

en el Campo de Montiel, junto al río Jabalón. En dicho centro, esta clase de cerámica comienza a aparecer en los niveles arqueológicos de finales del siglo V a.C. (Vélez-Pérez Avilés, 1987, 181), pero caracteriza sobre todo la fase comprendida entre mediados del siglo IV y finales del III a.C. (Vélez-Pérez Avilés, 1987, 181). Se trata de recipientes a los que se aplicó "tanto la pintura como las decoraciones de engobes (rojos, naranjas, marrones)", y desarrollan un programa decorativo basado en la combinación de bandas anchas con otras más estrechas en alternancia de colores, y de éstas con diversos motivos geométricos en color rojo: semicircunferencias y segmentos de circunferencias concéntricas (fig. $2, \mathrm{n}^{\mathrm{o}}$. 1, 2, 3 y 7), motivos ondulados (fig. 2, no .2 y 3), círculos, dientes de lobo, punteados, zig-zag, sigmas (Vélez-Pérez Avilés, 1987, 181). Asimismo, se documenta en el Cerro de las Cabezas un importante repertorio de estampillas (Almagro Gorbea, 1976-78, 136; Vélez-Pérez Avilés, 1987, 182; Blánquez-Roldán, 1995, 44, nº. 36; 50, nº. 45a y $\left.51, \mathrm{n}^{\mathrm{O}} .45 \mathrm{~b}\right)$, que decoran fundamentalmente cerámicas pintadas del tipo que tratamos (fig. 2, $\mathrm{n}^{\mathrm{o}} .1,5,6$ y 7), así como otros motivos impresos, generalmente cordones con series de trazos oblícuos incisos (fig. 2, $\mathrm{n}^{\mathrm{o}}$. 1, 5 y 7; Almagro Gorbea, 1976-78, 136, fig. 18; Blánquez-Roldán, 1995, 44, $\mathrm{n}^{\mathrm{o}} .36 ; 50, \mathrm{n}^{\mathrm{o}} .45$ a y $\left.51, \mathrm{n}^{\mathrm{o}} .45 \mathrm{~b}\right)$.

Entre las formas cerámicas sobre las que se aplicó esta modalidad decorativa se encuentran grandes ánforas o tinajas (Vélez-Pérez Avilés, 1987, 181; Blánquez-Roldán, 1995, 45, nº . 38a y 38b), urnas o tinajillas (fig. $2, \mathrm{n}^{\mathrm{O}} .1$ y 2 ; Almagro Gorbea, 1976-78, 136, fig. 18), cálatos de cuello estrangulado o tarros (Almagro Gorbea, 1976-78, 136, fig. 18; Vélez-Pérez Avilés, 1987, 181; Blánquez-Roldán, 1995, 44, nº 36 ), crateriformes (fig. 2, $\mathrm{n}^{\mathrm{o}} .3$ ), lebrillos o lebetas (fig. 2, $\mathrm{n}^{\mathrm{o}}$. 4), platos, páteras, jarros (Vélez-Pérez Avilés, 1987, 181 y 182), coladores y soportes (BlánquezRoldán, 1995, 50, núm. 45a y 51, núm. 45b). El hallazgo de un horno cerámico junto a gran número de piezas, o de una matriz de estampillas, hace plantear la posibilidad de que el centro fuera productor y distribuidor de este tipo de cerámicas (Vélez-Pérez Avilés, 1987, 182).

Hay también constancia de la existencia de 


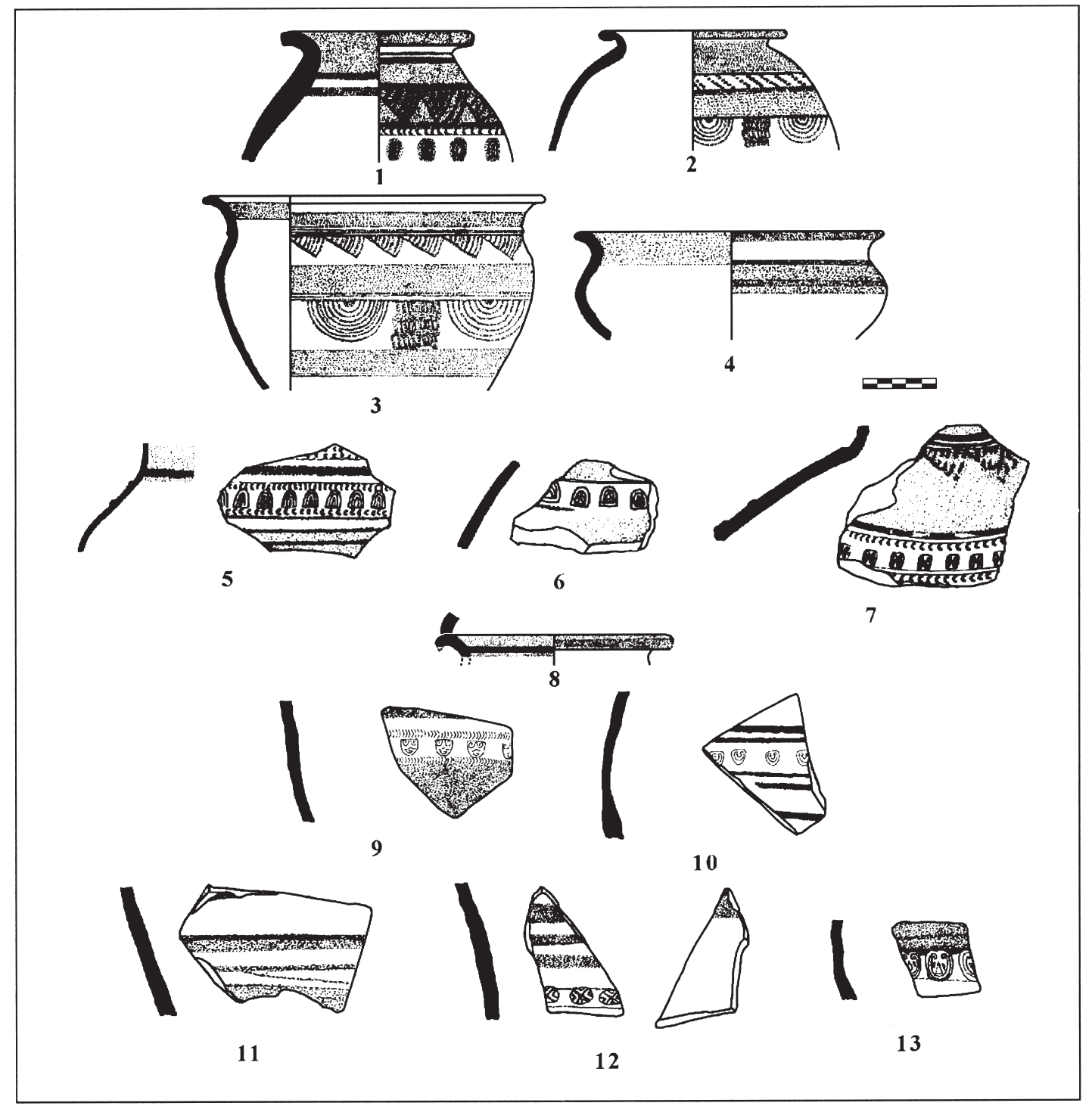

Fig. 2. Hallazgos de cerámica a torno pintada tipo Valdepeñas: 1-7, Cerro de las Cabezas (elaborado a partir de Vélez-Pérez Avilés, 1987 y Almagro Gorbea, 1976-78); 9-10, Almedina (elaborado a partir de Pérez Avilés, 1985); 11-13, La Pizarrilla (elaborado a partir de Pérez Avilés, 1985).

este tipo de alfarería, a través de hallazgos efectuados en prospecciones, en otros yacimientos del Campo de Montiel, tales como Almedina (Ciudad Real) (fig. 2, núm. 8, 9 y 10; Pérez Avilés, 1985, 187; Pérez, 1987, 204), La Pizarrilla (Cózar, Ciudad Real) (fig. 2, núm. 11, 12 y 13; Pérez Avilés, 1985, 195 y 196) o el Villar o Molino de los Moros (San Carlos del Valle, Ciudad Real) (Alañón, 1988, 141).

Otro de los principales conjuntos excavados de cerámica bícroma del tipo Valdepeñas es el procedente de Cerro Domínguez, (Granátula de Calatrava, Ciudad Real), yacimiento situado más hacia occidente, en el Campo de Calatrava, también junto al río Jabalón, tradicionalmente identificado como la antigua ciudad de Oreto. Es característica entre los materiales pintados del estrato I del área $\mathrm{K} / 10$ (siglo IV a.C.) la combinación de engobe, pintura y estampillas (NietoSánchez Meseguer-Poyato, 1980, 58), así como también en diversos estratos fechados en el periodo ibérico de la subárea K/D (NietoSánchez Meseguer-Poyato, 1980, 50-58), donde el tipo parece llegar hasta el siglo II a.C., aunque esta cronología avanzada no parece frecuente si se analizan el resto de los hallazgos de esta cerámica, por lo que los datos de estos estratos de Oreto han de tomarse con cierta precaución. Esta decoración aparece sobre tinajas (fig. 3, núm. 1), un conjunto numeroso de tinajillas (fig. 3, núm. 2-11 y fig. 4, núm. 1, entre muchas otras), tarros (fig. 3, núm. 12 y 13), crateriformes (fig. 3, núm. 14 y 15), lebetas o lebrillos (fig. 3, núm. 16), 


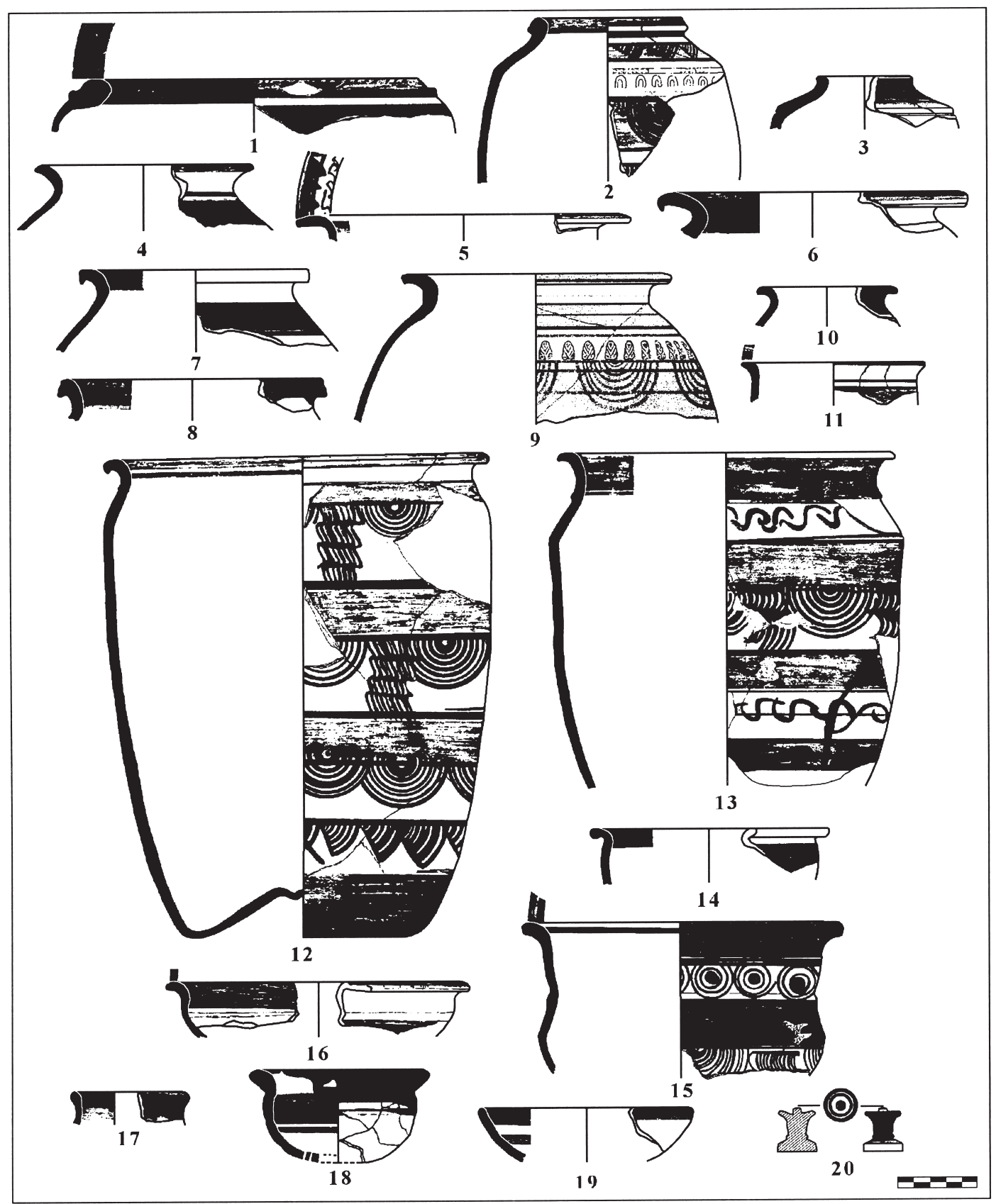

Fig. 3. Hallazgos de cerámica a torno pintada tipo Valdepeñas: 1-20, Cerro Domínguez (elaborado a partir de Nieto-Sánchez Meseguer-Poyato, 1980).

platos (fig. 3, núm. 19), coladores (fig. 3, núm. 18) u otras formas diversas (fig. 3, núm. 17 y 20).

Son numerosos los ejemplos de decoraciones mediante la combinación en bicromía de bandas anchas y estrechas con los motivos típicos dela producción, tales como circunferencias, semicircunferencias y segmentos de circunferencias concéntricas, ondulados, reticulados, triángulos (fig. 3 , núm. $5,12,13$, 15; fig. 4 , núm. 1 y 6 ), así como estampillas en combinación de algunos de estos motivos (fig. 3, núm. 9; fig. 4, núm. 2-4) o cordones con series de impresiones o incisiones obli- cuas (fig. 3, núm. 2; fig. 4, núm. 5) idénticas a las documentadas en materiales del Cerro de las Cabezas (fig. 2, núm. 1, 5 y 7; Almagro Gorbea, 1976-78, 136, fig. 18; Blánquez-Roldán, 1995, 44, núm. 36; 50, núm. 45a y 51, núm. 45b) o Almedina (fig. 2, núm. 9); ejemplares significativos pueden observarse incluso en los estratos más superficiales de las diversas áreas (fig. 3, núm. 2, 10, 12 y 13; Nieto-Sánchez MeseguerPoyato, 1980, fig. 83, núm. 50; fig. 93, núm. 171; fig. 97, núm. 218).

Otros yacimientos del Campo de Calatrava 
con niveles de cronología ibérica plena han proporcionado hallazgos de cerámicas bícromas del tipo que venimos tratando. Es el caso del Cerro de Alarcos (Ciudad Real), junto al Guadiana, (fig. 5, núm. 1-4; Gil Farrés, 1952, fig. 1 y 2; Fernández Rodríguez, 1987, 69), o la Motilla de los Palacios (Almagro, Ciudad Real) (Fernández Rodríguez-Fonseca, 1985, 265). En este último caso, las piezas se han fechado por cuestiones tipológicas en el siglo III a.C. Se trata de una tinajilla (fig. 5, núm. 5), dos tarros (fig. 5, núm. 6 y 7), un caliciforme (fig. 5, núm. 8) y un plato (fig. 5 , núm. 9) que presentan decoración en rojo y negro o rojo y ocre, aunque las características decorativas y los esquemas utilizados son idénticos a las de las cerámicas a torno pintadas del tipo Valdepeñas que hasta ahora hemos mencionado. También se han hallado cerámicas de esta clase en la Motilla de la Isla de Las Cañas (Daimiel, Ciudad Real) (Molina-Carrión-BlancoContreras-López, 1983, 312; López Rozas, 1987, 345 y 346$)$.

Uno de los principales conjuntos de cerámica a torno pintada tipo Valdepeñas procede sin embargo de un centro situado algo alejado del grueso de los hallazgos. Es el excavado en La Bienvenida (Almodóvar del Campo, Ciudad Real), en el Valle de Alcudia, espacio de transición hacia Sierra Morena en el sur de la Meseta.
La cerámica a torno pintada del yacimiento, identificado como la antigua Sisapo (Fernández Ochoa-Caballero Klink-Morano, 1982-83; Fernández Ochoa-Zarzalejos-Hevia-Esteban, 1994), ha sido objeto de un estudio monográfico reciente (Esteban, 1998), en el cual han podido identificarse a lo largo del desarrollo protohistórico e histórico del centro, una serie de grupos o clases de cerámicas susceptibles de ser considerados producciones o conjuntos de producciones de uno o varios alfares interrelacionados.

El más importante entre los grupos cerámicos surgidos durante el periodo ibérico pleno de Sisapo es sin duda el denominado grupo 5, no sólo por su preponderancia numérica sino, ante todo, por sus características técnicas singulares, coincidentes con las de las producciones del tipo Valdepeñas. Sus ejemplares presentan cocción oxidante o mixta, con pasta anaranjada (de nucleo gris cuando se trata de cocción mixta) de aspecto muy compacto y desgrasantes finos o muy finos. Los acabados de las piezas presentan a veces alisados o bruñidos en determinadas zonas. Es ante todo característica su decoración bícroma, mediante los colores rojo vinoso y anaranjado combinados con espacios en reserva, así como la utilización con mayor o menor intensidad del primer color. A menudo se realiza un lustrado de la pintura, lo que confiere un aspecto de

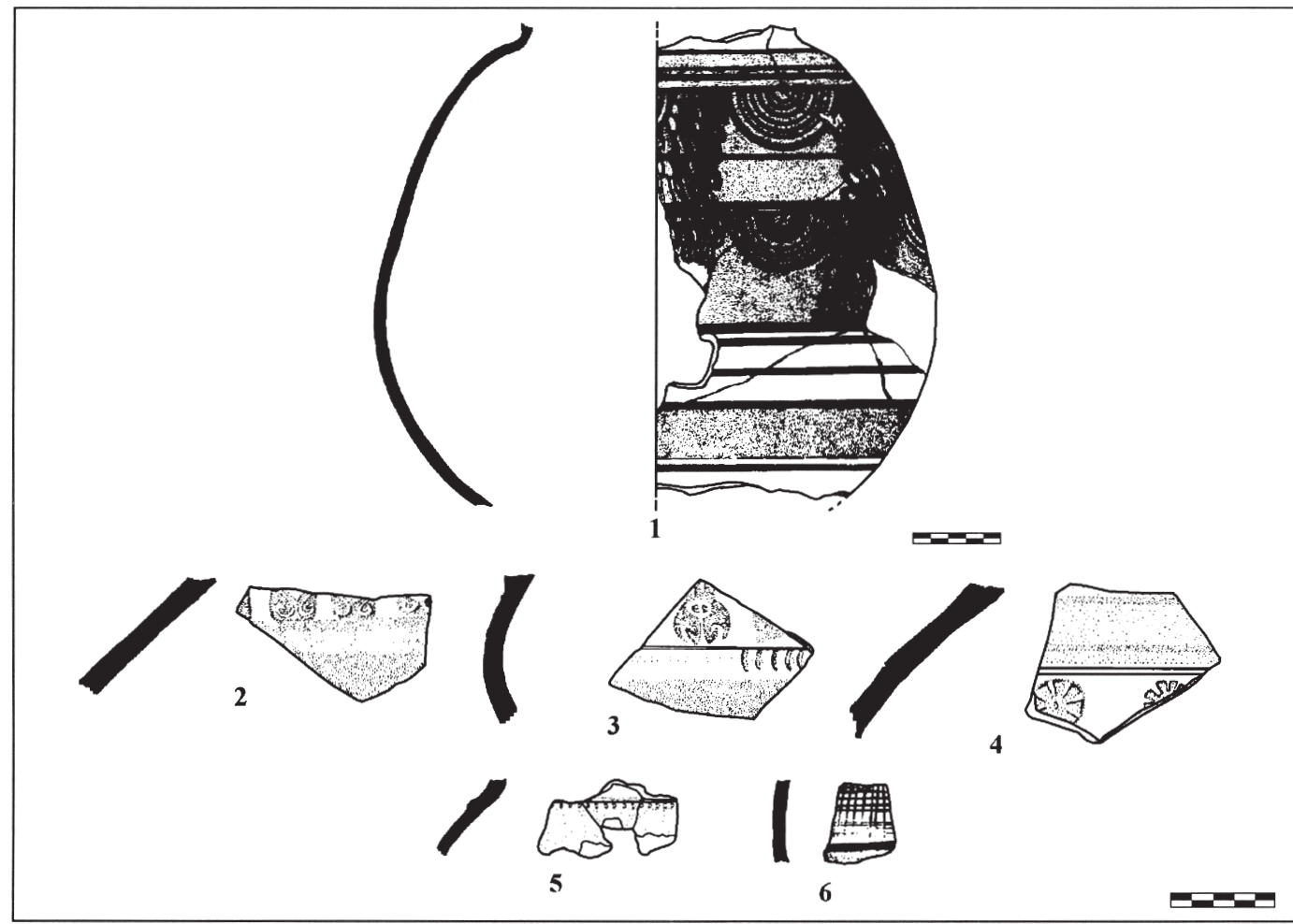

Fig. 4. Hallazgos de cerámica a torno pintada tipo Valdepeñas: 1-6, Cerro Domínguez (elaborado a partir de Nieto-Sánchez Meseguer-Poyato, 1980). 




Fig. 5. Hallazgos de cerámica a torno pintada tipo Valdepeñas: 1-4, Alarcos (elaborado a partir de Fernández Rodríguez, 1987); 59, Motilla de los Palacios (elaborado a partir de Fernández Rodríguez-Fonseca, 1985).

gran calidad a las piezas. Resulta importante haber identificado ejemplares monócromos en rojo vinoso pertenecientes también a este mismo grupo, aunque la fragmentación del conjunto es determinante en este aspecto. El análisis físicoquímico efectuado en una pieza correspondiente al grupo 5 (Vigil-García Giménez, 1998) evidencia una pasta cerámica muy fina, con engobe amarillo (calcita), poros, huecos y pequeños desgrasantes, entre los que cabe destacar esporádicos fósiles procedentes de rocas calizas sedimentarias. La presencia de abundante componente orgánico, especialmente grafito, demuestra que la temperatura de cocción de la pieza no fue superior a 550 grados centígrados. La documentación de hematites ha de ponerse en relación con la decoración pintada. Entre los componentes químicos cabe mencionar la presencia de plomo.
Respecto a las decoraciones, las bandas (fig. 6, núm. 1-23) y lineas (fig. 6, núm. 6, 9, 11, 12, 16, 20 y 21) muestran proporciones importantes. Predomina la combinación bícroma de bandas estrechas o lineas de color rojo vinoso con bandas anaranjadas anchas en la zona del borde y cuello fundamentalmente (fig. 6, núm. 1, 3, 6, 8, 11-16 y 19). En ocasiones las bandas se extienden al interior del cuello (fig. 6, núm. 8 y 19), y es también habitual el uso de superposiciones de lineas rojas sobre bandas anaranjadas (fig. 6, núm. 11), o de combinaciones de bandas y lineas vinosas de distinta intensidad (fig. 6, núm. 8). Las bandas y lineas aparecen combinadas (en esto la fragmentación se muestra como claro impedimento al analisis) a cierta diversidad de motivos, representados siempre en tono rojo vinoso. Entre éstos destaca la presencia, en importante proporción, de circunferencias con- 


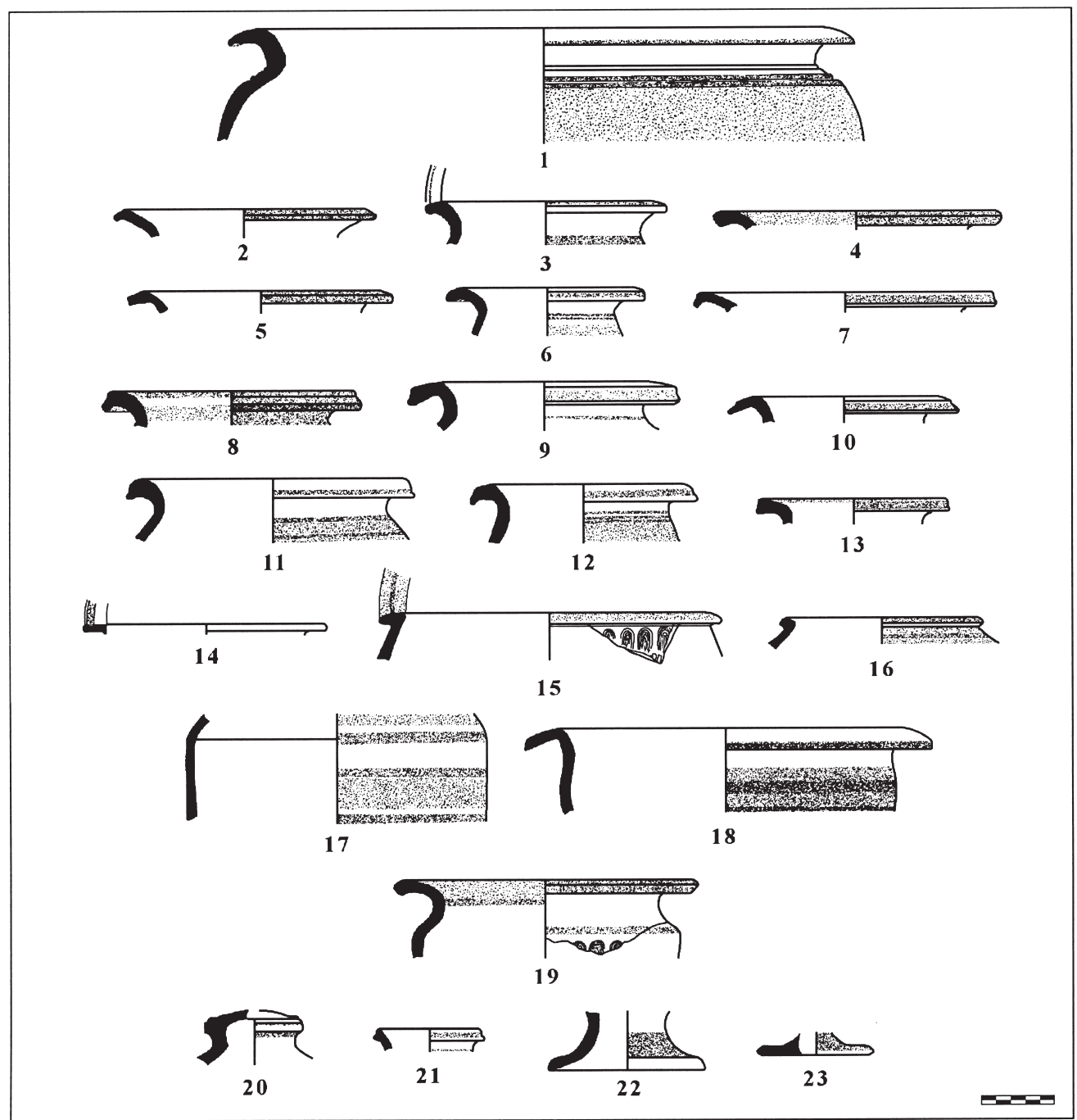

Fig. 6. Hallazgos de cerámica a torno pintada tipo Valdepeñas: 1-23, La Bienvenida (elaborado a partir de Esteban, 1998).

céntricas, el 48,7\% del total de este motivo entre las cerámicas pintadas de poca orientalizante e ibérica del yacimiento, semicircunferencias concéntricas (fig. 7, núm. 1 y 3), el 35,7\%, y los motivos ondulados (fig. 7, núm. 3), el 37,5\% del total. Aparecen por vez primera entre las cerámicas pintadas del centro otros motivos, tales como los segmentos de circunferencias concéntricas (fig. 7, núm. 2), que constituyen el $50 \%$ de las totales, los reticulados (fig. 7 , núm. 4 y 5), el 66,6\%, o los motivos impresos mediante estampillas. Estos presentan en La Bienvenida el 80\% de sus manifestaciones sobre piezas del grupo 5. Los ejemplos documentados pueden encuadrarse en el tipo BV de Ruiz Rodríguez y Nocete (Ruiz Rodríguez-Nocete, 1981, 356 y 357), que desarrolla motivos curvilineos no cerrados, en este caso ovas (Mata, 1985, 172) (fig. 6, núm. 19), ovas combinadas con cordones aplicados incisos (fig. 6, núm. 15) idénticos a los de piezas del Cerro de las Cabezas (fig. 2, núm. 1, 5 y 7; Almagro Gorbea, 1976-78, 136, fig. 18; Blánquez-Roldán,
1995, 44, núm. 36; 50, núm. 45a y 51, núm. 45b), Almedina (fig. 2, núm. 9) u Oreto (fig. 3, núm. 2; fig. 4, núm. 5), u ovas limitadas en su parte inferior por dos trazos impresos (fig. 7, núm. 6).

Entre las cerámicas de la clase 5 de La Bienvenida se ha documentado una apreciable variedad formal: tinajas (fig. 6 , núm. 1), tinajillas (fig. 6, núm. 2-16), tarros (fig. 6, núm. 17-19), caliciformes, tapaderas (fig. 6, núm. 20), botellas (fig. 6, núm. 21), y copas (fig. 6, núm. 22 y 23).

El grupo 5 es el predominante de los identificados entre las cerámicas a torno pintadas del periodo ibérico pleno de Sisapo, con el 47,3\% de los fragmentos documentados. Se trata de un grupo centrado precisamente en estos estratos (9a, 8, y 7), de mediados del siglo $\mathrm{V}$ a.C. a inicios del III a.C., en los cuales se ha excavado el 100\% de las piezas del mismo, a excepción de algunos fragmentos procedentes de estratos superiores, descontextualizados.

Junto a las cerámicas pintadas del grupo 5, 


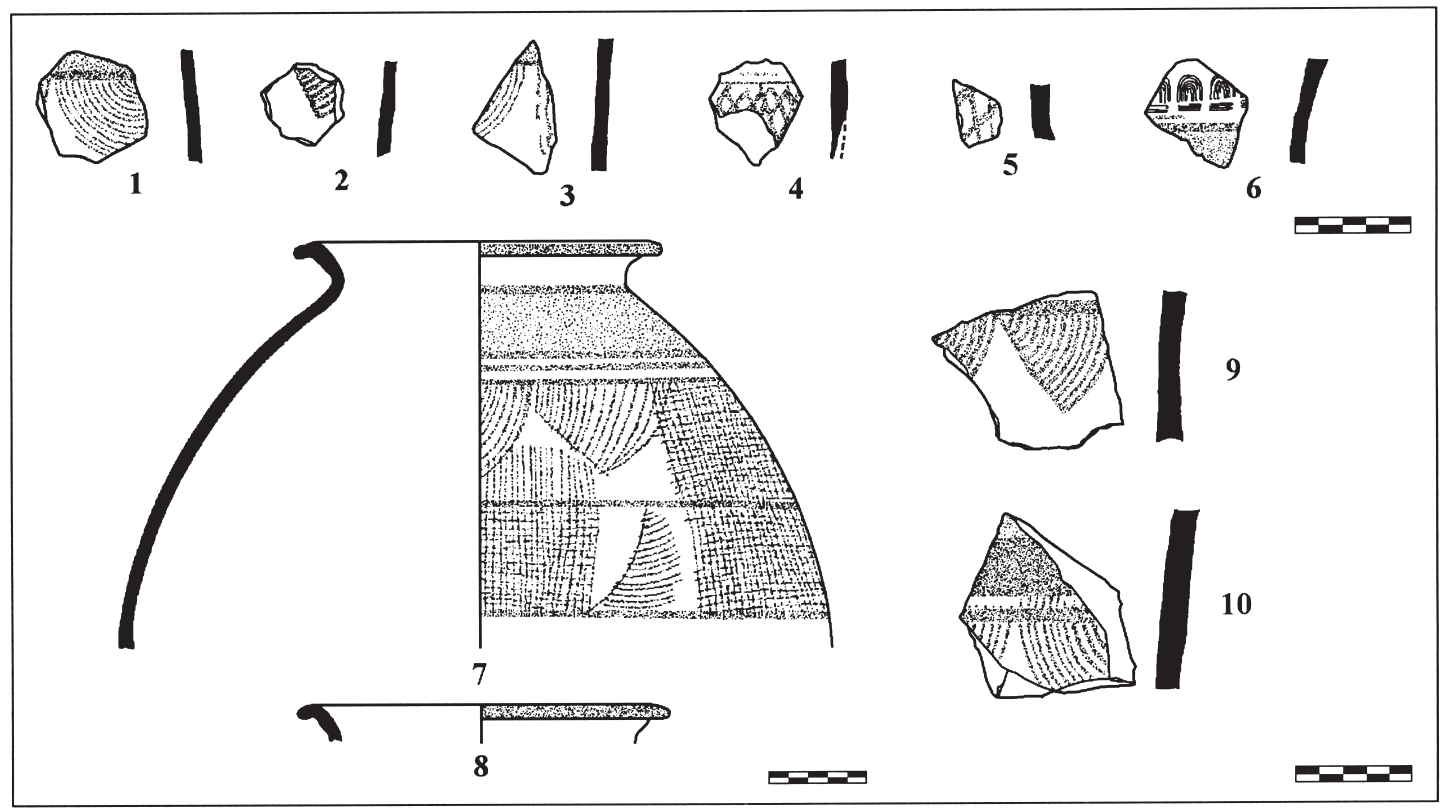

Fig. 7. Hallazgos de cerámica a torno pintada tipo Valdepeñas: 1-10, La Bienvenida (elaborado a partir de Esteban, 1998).

aparecen a partir del estrato 7c del periodo ibérico pleno de La Bienvenida (primera mitad del siglo IV a.C.) algunos otros fragmentos (19, 2,3\% del total), con características algo divergentes a éstas, que han sido individualizados formando el grupo 7. Las piezas presentan cocción oxidante, pasta ocre claro, desgrasantes muy finos y bicromía en rojo vinoso y anaranjado (se han individualizado también fragmentos monócromos en rojo). El análisis físico-químico de una muestra del grupo 7 (Vigil-García Giménez, 1998) resulta determinante para la caracterización de dicho grupo cerámico. Entre los componentes minerales de la misma se encuentra el olivino, mineral de origen volcánico que evidencia un aprovisionamiento de desgrasante y, probablemente, una fabricación local o regional (Campo de Calatrava) de la pieza y, por tanto, del grupo; a tal extremo parece apuntar igualmente la presencia de plata.

El estilo decorativo de las piezas de este grupo es muy característico, debido al dibujo un tanto irregular y descuidado de los motivos. Se documentan en la clase 7 la banda (fig. 7, núm. 7-10), la linea (fig. 7, núm. 7 y 10), las semicircunferencias concéntricas (fig. 7, núm. 10), los segmentos de circunferencias concéntricas (fig. 7, núm. 7, 9 y 10), y el reticulado (fig. 7, núm. 7), estos tres últimos motivos en una proporción considerable. La peculiaridad en el modo y esquema decorativo del grupo puede observarse en una tinajilla del estrato 7c (fig. 7, núm. 7).

Precisamente, únicamente se ha documentado la tinajilla entre las formas representadas en este grupo (fig. 7, núm. 7).
El grupo 7 constituye, con toda seguridad dado los análisis físico-químicos, una producción local o regional del Campo de Calatrava. Debe ponerse en relación con el grupo 5 y por tanto con las producciones cerámicas bícromas de tipo Valdepeñas, mostrandose como una especie de imitación tosca de estas, al desarrollar una decoración en rojo y anaranjado de trazo un tanto descuidado en ocasiones, y siempre de peor calidad en los acabados.

Las importantes relaciones culturales del área de Valdepeñas con la Alta Andalucía apuntadas por diversos investigadores (Almagro Gorbea, 1976-78, 134-136; Blasco, 1992, 293) se muestran nítidamente en el aspecto material, y, de modo contundente, en el caso de la cerámica a torno pintada. Precisamente en la Alta Andalucía, la decoración bícroma de las cerámicas pintadas, empleando los tonos marrones violaceos, naranjas y rojos, se muestra como uno de los rasgos principales de un periodo desarrollado a partir de mediados del siglo IV a.C. o quizás desde finales del siglo V (Ruiz Rodríguez-Molinos-HornosChoclán, 1987, 242-243), hecho que creemos posible relacionar muy directamente con el desarrollo de la producción de cerámicas en rojo y anaranjado en la citada zona de la Meseta.

El desarrollo de la bicromía o policromía en las series cerámicas a torno aparece ligado en la Alta Andalucía a los mismos comienzos del iberismo, y caracterizó a producción, desde finales del siglo VI a.C. y hasta el periodo ibérico pleno, de centros de extraordinaria vitalidad, como es el caso de Toya (Peal de Becerro, Jaén) (Pereira, 1979). El desarrollo de decoraciones bícromas 
está también atestiguado en la necrópolis de la Bobadilla (Jaén) durante los siglos VI y V a.C., entre las piezas de un conjunto muy homogéneo, probablemente procedente de un mismo alfar (Maluquer-Picazo-Rincón, 1973, 50 y 51). En el periodo ibérico pleno encontramos un exponente lo suficientemente importante en Cástulo, de donde proceden una serie de piezas bícromas que combinan colores rojos con anaranjados $o$ mostazas, y que muestran gran analogía con las producciones que venimos comentando (fig. 8). Es preciso destacar diversos ejemplares de las necrópolis de los Patos, y de la necrópolis de Baños de La Muela, fechados a finales del siglo V y comienzos del IV a.C., (Blázquez, 1975), de la necrópolis del Estacar de Robarinas, con idéntica cronología (Gelabert-Blázquez, 1988), así como algunos ejemplos procedentes de sondeos (Blázquez-Contreras-Urruela, 1984). Entre las piezas se encuentran tinajas (fig. 8, núm. 1), tinajillas o urnas (fig. 8, núm. 2-10), tarros (fig. 8, núm. 11 y 12) y platos (fig. 8, núm. 13); los motivos decorativos desarrollados son las bandas anchas y estrechas combinadas en bicromía, aso- ciadas en ocasiones a motivos geométricos en rojo, tales como semicircunferencias concéntricas (fig. 8, núm. 16), segmentos de circunferencias concéntricas (fig. 8, núm. 9 y 17), trazos ondulados (fig. 8, núm. 19) o trazos rectilineos (fig. 8, núm. 18). Se dan también los motivos impresos: cordones con series de impresiones o incisiones oblicuas (fig. 8, núm. 20 y 21), desarrollados de modo idéntico al de las piezas ya mencionadas del Cerro de las Cabezas (fig. 2, núm. 1, 5 y 7; Almagro Gorbea, 1976-78, 136, fig. 18; Blánquez-Roldán, 1995, 44, núm. 36; 50, núm. 45a y 51, núm. 45b), Almedina (fig. 2, núm. 9), Oreto (fig. 3, núm. 2 y fig. 4 , núm. 3 y 5) o Sisapo (fig. 6, núm. 15); o estampillas (fig. 8, núm. 22)

La producción de estas cerámicas parece que pudo ser local, dada la existencia de alfares en las proximidades del centro, junto al rio Guadalimar (Blázquez-García Gelabert-López Pardo, 1985, 234; García Gelabert-Blázquez, 1988, 84), de los que proceden piezas tipológicamente muy cercanas (perfiles de pico de ánade en los bordes, molduraciones...) a las documentadas durante el

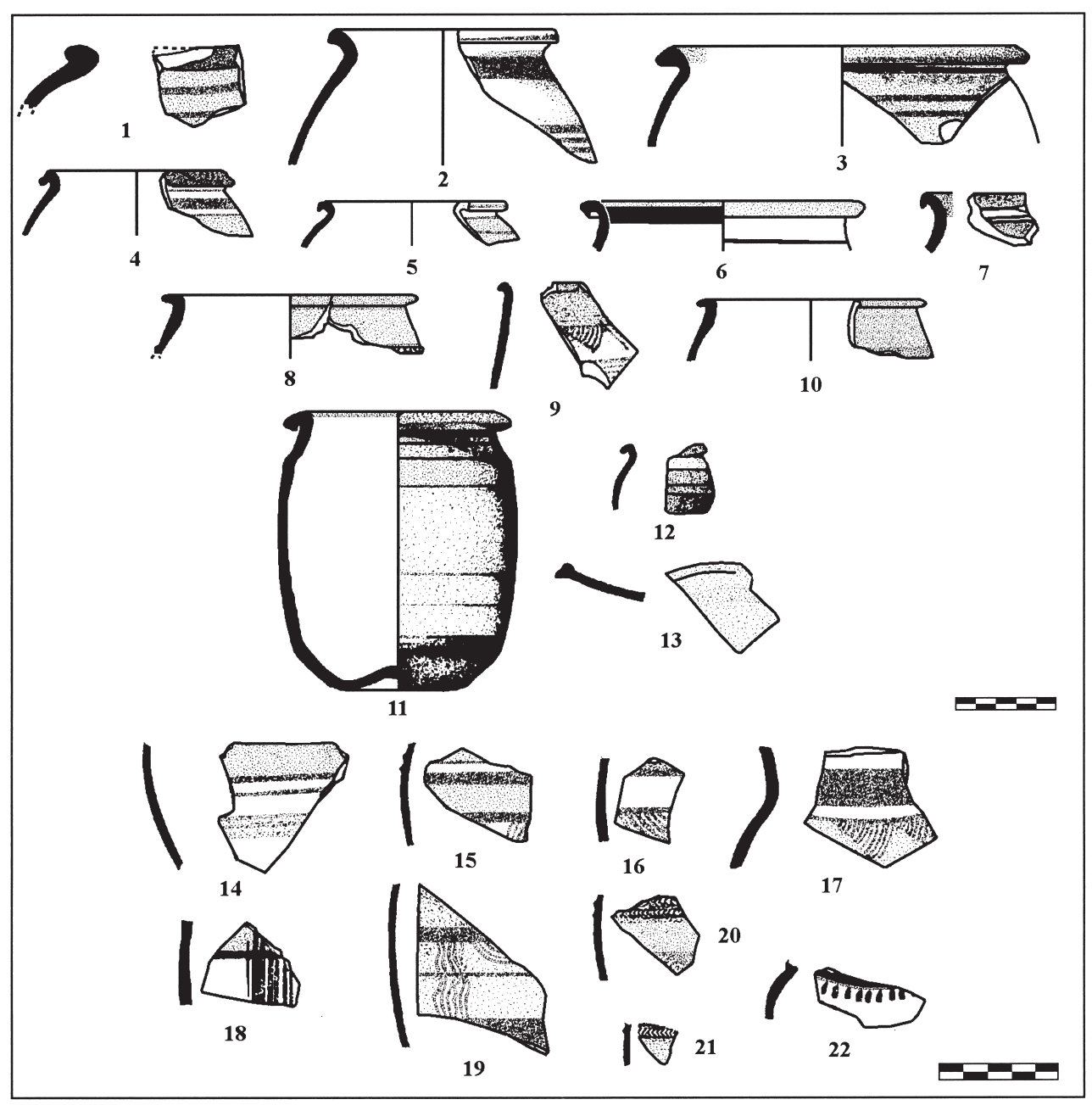

Fig. 8. Hallazgos de cerámica a torno pintada tipo Valdepeñas: 1-22, Cástulo (elaborado a partir de Blázquez, 1975, BlázquezContreras-Urruela, 1984 y García Gelabert-Blázquez, 1988). 


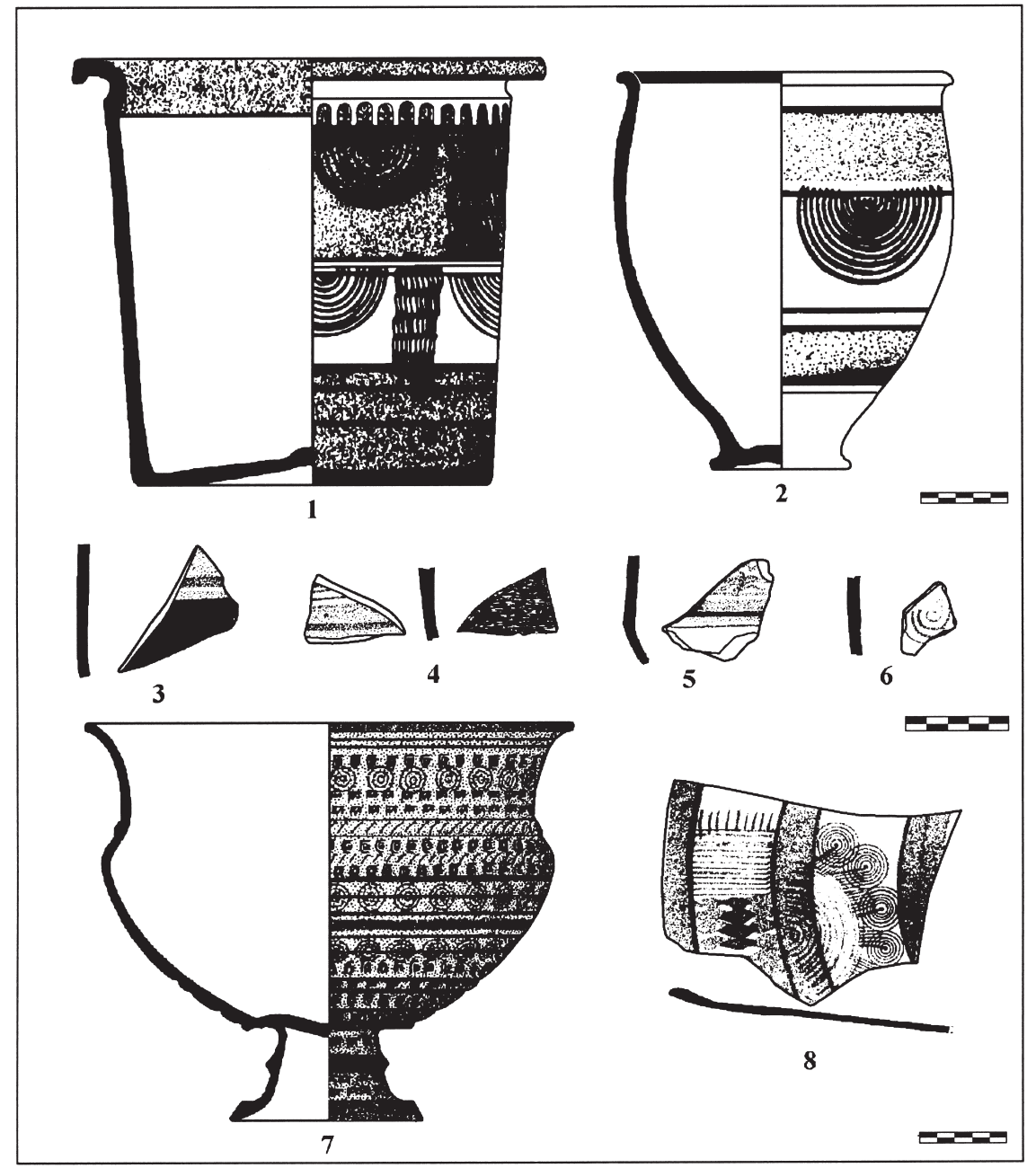

Fig. 9. Hallazgos de cerámica a torno pintada tipo Valdepeñas: 1-2, Palomar del Pintado (elaborado a partir de Carrobles-Ruiz Zapatero, 1990); 3-6, El Cerrón (elaborado a partir de Balmaseda Valiente, 1979); 7, Olmedilla de Alarcón (elaborado a partir de Almagro Gorbea, 1976-78); 8, Reillo (elaborado a partir de Almagro Gorbea, 1976-78).

periodo ibérico pleno en el área de Valdepeñas. Es necesario mencionar el importante repertorio de cerámicas estampilladas del Alto Guadalquivir (Ruiz Rodríguez-Nocete, 1981), con muchos tipos idénticos a los desarrollados en el sur de la Meseta.

El hallazgo de alfarería pintada del tipo Valdepeñas fuera de su área neurálgica de concentración se verifica hacia el norte en yacimientos de La Mancha como el poblado del Cerro de las Nieves (Pedro Muñoz, Ciudad Real) (comunicación personal de V. Fernández Martínez), o la necrópolis carpetana de Palomar del Pintado (Villafranca de los Caballeros, Toledo), con cronología desde la primera mitad del siglo IV a.C. (Carrobles-Ruiz Zapatero, 1990, 244 y 245). En ambos casos las piezas se encuentran intimamente relacionadas con las manifestaciones más meridionales del tipo cerámico; así, en Palomar del Pintado un tarro (fig. 9, núm. 1) y una especie de crateriforme (fig. 9, núm. 2) muestran la típica combinación de bandas rojas vinosas y bandas naranjas con motivos geométricos (semicircunferencias concéntricas y ondulados) en rojo vinoso, y motivos estampillados, que aparece de modo idéntico en piezas de Valdepeñas, Oreto o La Bienvenida.

Más al norte, la presencia de cerámicas pintadas emparentadas con el tipo Valdepeñas se atestigua en El Cerrón (Illescas, Toledo), donde se ha documentado un conjunto de piezas a torno decoradas mediante engobes semivitrificantes y motivos de bandas, circunferencias y semicircunferencias concéntricas en pinturas rojas, anaranjadas, ocres y negras, a menudo lustradas o bruñidas (fig. 9, núm. 3-6; Balmaseda-Valiente, 1979, 189), que los excavadores han puesto en relación con piezas de Oreto (Balmaseda-Valiente, 1979, 194). Se dan también los motivos estampillados, así como ejemplares de barniz rojo (BalmasedaValiente, 1979, 190; Valiente 1994, 87-89, por ejemplo fig. 33 o fig. 43). Este elenco cerámico 
procede de los niveles más antiguos del lugar, fechados en la primera mitad del siglo IV a.C., en los que se detecta una relación material intensa con la Alta Andalucía a través de las tierras de Ciudad Real (Balmaseda-Valiente, 1979, 150). Hacia el norte, en la provincia de Madrid, existen conjuntos cerámicos que quizás puedan relacionarse con el tipo de alfarería al que estamos refiriéndonos (Blasco-Alonso, 1983, 124), como también atestiguan tal vez otros documentos cerámicos de la provincia de Toledo (ValienteBalmaseda, 1983, 141; Valiente, 1987, 131). Asimismo, no podemos dejar de plantear la posible relación entre la cerámica pintada tipo Valdepeñas y la denominada cerámica jaspeada, característica del ámbito carpetano durante los siglos IV y III a.C. (Valiente-Balmaseda, 1983, 141), que en ocasiones muestra combinación de engobes de diversas tonalidades así como engobes asociados a bandas pintadas o estampillas (Valiente, 1987, 131). Las cerámicas jaspeadas aparecen habitualmente junto a cerámicas pintadas y estampilladas de tipo ibérico (Valiente, $1987,131)$, por lo que es muy probable la relación de dependencia entre ambas clases; de este modo, la producción pintada bícroma en rojo y naranja y las manifestaciones jaspeadas bícromas o polícromas o en combinación con bandas pintadas y estampillas pueden estar relacionadas en un grado que todavía es dificil de establecer.

Es necesario considerar, en última instancia, el hallazgo de un gran crateriforme con engobe anaranjado, decoración de bandas y circunferencias concéntricas en tono rojo vinoso, bruñido y con desarrollo de motivos estampillados con claros paralelos en Valdepeñas, Oreto o Cástulo, de la necrópolis de Olmedilla de Alarcón (Cuenca) (fig. 9, núm. 7; Almagro Gorbea, 1976-78, 138; Mena, 1984, fig. 42, núm. 145; 119 y 126), así como de piezas a torno pintadas bícromas en rojo vinoso y sepia con decoración concéntrica e incluso estampillas en Reillo (Cuenca) (fig. 9, núm. 8; Almagro Gorbea, 1976-78, 150), para encontrar indicios de la influencia de la alfarería pintada tipo Valdepeñas en otros lugares más nororientales. Hacia el este el único documento que puede indicar una difusión del tipo lo constituye una botella decorada mediante alternancia de lineas rojas y bandas anaranjadas procedente de El Amarejo (Bonete, Albacete) (BlánquezRoldán, 1995, 42), que hay que situar dentro del siglo III a.C. (Broncano-Blánquez, 1985).

La alfarería a torno pintada bícroma o polícroma está presente, de modo más aislado, en otras áreas peninsulares durante el periodo ibérico pleno. Es el caso, entre otras, de las manifestaciones extremeñas en negro y rojo (Rodríguez
Díaz, 1989, 190), u otras diversas halladas en Levante y el Sureste. Estas últimas, atrajeron en un momento temprano la atención de la investigación (Vall-Pla, 1969; Aranegui, 1974), que consideró las piezas como posibles importaciones (Vall-Pla, 1969, 295; Aranegui, 1974, 99) dada su presencia excepcional en estas zonas, en contraste con su frecuencia en tierras de la Alta Andalucía (Oliver, 1982-83, 202). No obstante el hallazgo de cerámica a torno pintada bícroma del periodo ibérico pleno en Levante es cada vez más frecuente (por ejemplo Aranegui-Martí, 1995), pero parece por sus características desvinculada de la producción a la que estamos refiriendonos. Por su parte, la repercusión de la producción cerámica pintada tipo Valdepeñas en la Baja Extremadura parece bastante nula por lo que muestra hasta hoy la investigación arqueológica, con la excepción que significa el fenómeno de la decoración pintada y estampillada (Rodríguez-Díaz, 1989, 190 y 191), que emparenta dichas manifestaciones extremeñas con otras similares, como las cerámicas estampilladas del suroeste de la Meseta castellana, entre las que se cuentan las producciones del tipo Valdepeñas. Este hecho no deja de ser llamativo teniendo en cuenta la profunda ligazón que mantuvo la zona suroccidental de Castilla con el ámbito extremeño durante el periodo orientalizante (Zarzalejos, 1994, 840-856; Esteban-Hevia, 1996, 537-538; Esteban, e.p.).

\section{CONCLUSIONES: PRODUCCIONES CERÁMICAS ORETANAS DEL PE- RIODO IBÉRICO PLENO}

A raíz de lo expuesto es posible afirmar que la cerámica a torno pintada bícroma del tipo referido constituye un tipo característico del periodo ibérico pleno que, dentro de la Meseta, aparece concentrada en un espacio principal que puede adscribirse al área de Valdepeñas. En esta zona debieron existir diversos alfares que la fabricaron, como es el caso del existente posiblemente en el propio Cerro de las Cabezas (Vélez-Pérez Avilés, 1987, 182) y, tal vez, del alfar que abasteció a la Motilla de los Palacios. Asimismo la comercialización de cerámicas del tipo desde estos talleres debió ser muy importante a juzgar por su presencia en gran cantidad en todos los yacimientos contemporáneos del área.

Es perceptible, sin embargo, la extensión al suroeste en la dispersión del tipo, hacia la periferia minera de Sisapo, donde se ha identificado a partir de las piezas del grupo 7 un taller del Campo de Calatrava, que compite en el mismo centro con las producciones del grupo 5, de 
mayor calidad, muy similares a las de conjuntos como el del Cerro de las Cabezas u Oreto. Asimismo se verifica la presencia de esta alfarería al noreste, en centros del área manchega (Almagro Gorbea, 1976-78, 136-138), zona con un sustrato y unas relaciones culturales netamente diferenciadas a las del área de Valdepeñas (Fernández Martínez-Hornero-Pérez Muga, 1994, 118 y 121; Esteban-Hevia, 1996), donde sin embargo aparecen piezas tales como las del Cerro de las Nieves o Palomar del Pintado, idénticas en sus características a las de los principales conjuntos de dicha área, por lo que deben responder a intercambios comerciales. De igual modo, es necesario dar cuenta de la influencia de la alfarería considerada hacia lugares más alejados, comprendidos dentro de las denominadas por Almagro Gorbea área toledana, área de la Serranía de Cuenca, área del sudeste de la Meseta (Almagro Gorbea, 1976-78, 130-134; 138 y 139; 144-150).

La existencia de relaciones entre los centros del área de Valdepeñas y algunas de estas otras regiones culturales fueron ya apuntadas por el propio investigador (Almagro Gorbea, 1976-78, 138), y se desarrollaron a lo largo de dos ejes fundamentales (oeste-este y noreste-suroeste) que señalan, momentáneamente (es necesario considerar el vacio actual de la investigación en numerosos puntos de la Meseta Sur), no sólo las áreas neurálgicas y los límites de un más que probable espacio común en el caso de los centros de la mitad sur de la provincia de Ciudad Real, sino también las rutas de intercambio efectivo, a raiz del cual creemos deben justificarse algunos hallazgos concretos de estas cerámicas, como ya hemos mencionado.

La alfarería de tipo Valdepeñas cuenta con precedentes y análogos contemporáneos en la Alta Andalucía. El caso más significativo es el de Cástulo donde cabe ubicar un alfar (BlázquezGarcía Gelabert-López Pardo, 1985, 234; García Gelabert-Blázquez, 1988, 84) que posiblemente fabricó durante el periodo ibérico pleno piezas de características muy similares (mismos esquemas decorativos pero en combinación bícroma de tonos rojo y marrón mostaza), aunque en el centro existen piezas idénticas a otras de la Meseta (cerámicas pintadas con combinaciones bícromas en rojo y anaranjado) que hacen pensar en intercambios comerciales entre ámbas zonas. La cultura material de la Alta Andalucía y el sur de la actual provincia de Ciudad Real muestra, durante el periodo ibérico pleno, probablemente desde finales del siglo $\mathrm{V}$ hasta bien entrado el siglo III a.C., una identidad palpable en lo que respecta a la cerámica a torno pintada, no solo en lo referente a aspectos decorativos (característica bicromía en rojo y anaranjado y desarrollo general de mayor variedad de motivos), sino también formales (diversificación muy importante de los tipos cerámicos, desarrollo de perfiles moldurados, especialmente en forma de pico de ánade en los bordes); pero asimismo en lo relacionado con otras manifestaciones materiales y sociales diversas, tales como la presencia masiva en ambas áreas de cerámicas griegas de barniz negro ático o de figuras rojas del grupo Viena 116 (NietoSánchez Meseguer-Poyato, 1980, 32; MolinaCarrión-Blanco-Contreras-López, 1983, fig. 9; Ruiz Rodríguez-Molinos-Hornos-Choclán, 1987, 243; Vélez-Pérez Avilés, 1987, 181; CabreraSánchez, 1994; Juan-Fernández RodríguezCaballero Klink, 1994, 151; Fernández OchoaZarzalejos-Hevia-Esteban, 1994, 150; ZarzalejosFernández Ochoa-Hevia-Esteban, 1995), la documentación de un importante número de piezas de barniz rojo ibérico de idéntica tipología (Nieto-Sánchez Meseguer-Poyato, 1980, 32; Almagro Gorbea, 1976-78, 134; Fernández Rodríguez, 1987; Ruiz Rodríguez-MolinosHornos-Choclán, 1987, 243; Vélez-Pérez Avilés, 1987, 181; Fernández Ochoa-Zarzalejos-HeviaEsteban, 1994, 150), o el desarrollo de gran estatuaria (Prada, 1977; Almagro Gorbea, 1976-78 134 y 136; Mena-Ruiz Prieto, 1985; Blasco, 1992, 293), santuarios (Caballero Klink-Mena, 1987; Juan-Fernández Rodríguez-Caballero Klink, 1994, 148 y 149) y la presencia, algo más adelante, de una orfebrería claramente emparentada (Álvarez Ossorio, 1945; Almagro Gorbea, 197678, 136; Patiño-González Garrido, 1985) en ambas zonas. Esta identidad común, más patente si restringimos el espacio observado a las tierras al norte de Sierra Morena, esencialmente al área de Valdepeñas, donde el sustrato cultural, el desarrollo urbano y, muy especialmente, el elenco material de los diversos centros aparecen, en la mayoría de las ocasiones, íntimamente relacionados (Esteban-Hevia, 1996).

Es posible que la clase de alfarería bícroma que hemos intentado definir lineas atrás alcanzase tal grado de importancia durante el periodo ibérico pleno en este amplio espacio de interrelaciones culturales que, a partir de la influencia de producciones de alfares primigenios, se conformase rápidamente un número importante de talleres locales, como parecen serlo el tal vez localizado en el Cerro de las Cabezas, el que abastece a la Motilla de los Palacios, el que produjo las piezas del grupo 7 de Sisapo, o el que confeccionó diversas piezas de Cástulo. En cualquier caso la documentación de producciones diferentes reproduciendo un tipo cerámico muy 
determinado demuestra la popularidad que este llegó a alcanzar en el área de Valdepeñas y diversas zonas limítrofes durante el periodo ibérico pleno y, por tanto, la vitalidad en las relaciones internas dentro de este espacio y la capacidad de algunos de sus centros para extender su influencia cultural (comercial seguramente) a lugares relativamente alejados del mismo.

La caracterización de esta clase cerámica, que constituye un magnífico fosil-guía cultural y cronológico, está basada en el análisis de los aspectos formales y decorativos, así como en los técnicos descritos para cada uno de los casos tratados. La confirmación de una producción única o de varias producciones locales pasa por la realización de análisis físicos-químicos de diversas piezas del repertorio total. El análisis de piezas pertenecientes al grupo 5 y 7 de Sisapo (VigilGarcía Giménez, 1998) puede significar un primer paso para un conocimiento más en profundidad del conjunto.

Es necesario considerar diversos centros del territorio que señala la dispersión de la cerámica a torno pintada de tipo Valdepeñas como integrantes de una economía interrelacionada y global que se desarrolla canalizada a través de diversas rutas o caminos, algunos de los cuales han podido determinarse hace tiempo, reconocidos a partir de la dispersión de determinados tipos de importaciones mediterráneas proporcionadas por el comercio focense. A partir del periodo ibérico antiguo y, más acusadamente, durante el periodo ibérico pleno, es posible verificar rutas que comunican el área de Sisapo y Valdepeñas con la Alta Andalucía (Cástulo) (Cabrera, 1987, 220; Domínguez Monedero, 1988, 333; Blánquez, 1990, 452; Zarzalejos, 1994, 149 y 150), Levante y el Sureste (Maluquer, 1985, 22-24; Blánquez, 1990, 452; Zarzalejos, 1994, 149 y 150), e incluso con la zona de la Baja Extremadura (Maluquer, 1985, 22-24; Cabrera, 1987, 220; Zarzalejos, 1994, 149 y 150), además de las citadas rutas de comunicación que pueden establecerse en la Meseta Sur a través de la dispersión e influencia de la cerámica a torno pintada tipo Valdepeñas y otras manifestaciones. Algunas de ellas son preexistentes en el momento orientalizante, como es el caso del camino de unión con la zona extremeña (Zarzalejos, 1994, 135 y 136; 149 y 150) y, probablemente, la ruta de contacto con Cástulo, si consideramos diversos hitos materiales presentes en La Bienvenida y el centro jienense (cerámica a mano pintada) (Esteban, e.p.); todas ellas parecen utilizarse en la época ibérica, pese a que es posible detectar la menor frecuentación del camino hacia Extremadura en estos momentos
(Zarzalejos, 1994, 148 y 149). La penetración desde las zonas costeras mediterráneas hacia esta zona, o hacia los grandes nucleos de Sierra Morena, en el centro de todas estas comunicaciones, ha de ponerse en relación con la comercialización de los recursos mineros del interior peninsular a través de centros como Sisapo o Cástulo, capaces de atender la demanda externa de oro, plata, cobre, estaño, o plomo (Maluquer, 1985, 23 y 24; Cabrera, 1987, 220; Blánquez, 1990, 429, 439 y 452; Zarzalejos, 1994, 136 y 137) y tal vez mercurio (Maluquer, 1985, 24; Domínguez Monedero, 1988, 332 y 333; Zarzalejos, 1994, 136 y 137).

La cultura material análoga y la economía intimamente relacionada en un espacio geográfico amplio en torno a importantes nucleos mineros de Sierra Morena parecen rasgos lo suficientemente expresivos para considerar éste, desde al menos el periodo ibérico pleno, como el área de influencia del pueblo oretano del que nos informan las fuentes escritas greco-latinas en un momento más avanzado al que nos venimos refiriendo (Fernández Ochoa-Caballero Klink, 1986, 37-40; Carrasco Serrano, 1988, 21; BlázquezGarcía Gelabert, 1992, 45 y 46; González Conde, 1992, 302-309; López Domech, 1996). En este sentido apunta la comunidad cultural existente en el periodo ibérico pleno entre los yacimientos de la Alta Andalucía y los del área de Valdepeñas (Ruiz Rodríguez, 1992, 116), que se acentúa entre los centros de la última zona mencionada. Ésta, pudo corresponder al espacio geográfico en que se desarrolló una de las dos grandes etnias o grupos que las fuentes antiguas parecen diferenciar entre los pueblos oretanos (González Conde, 1992, 302), aunque evidentemente la posesión de unos rasgos materiales determinados en un área concreta no resuelve las cuestiones relacionadas con la naturaleza étnica de sus pobladores. El desarrollo de la cultura material definida aquí sólo a grandes rasgos, de la que es elemento especialmente expresivo la cerámica a torno pintada bícroma tipo Valdepeñas, en centros identificados por la moderna investigación como antiguas ciudades oretanas mencionadas en las fuentes, tales como Cástulo (Blázquez, 1975), Oretum Germanorum (Oreto) (Nieto-Sánchez MeseguerPoyato, 1980, 16-11), Lacurris (Alarcos) (Fernández Rodríguez-Juan-Caballero Klink, 1993, 38), o de acuerdo a la cita ptolemaica (II, 6,58 ) (ya que Plinio incluye la ciudad dentro de la Beturia Túrdula) Sisapo (La Bienvenida) (Fernández Ochoa-Caballero Klink-Morano, 1982-83), parece evidenciar una etapa temprana en la configuración de este pueblo prerromano, como ha manifestado, manejando diversos argu- 
mentos, A. Ruiz Rodríguez (Ruiz Rodríguez, 1992, 116; Ruiz Rodríguez, 1997, 67-69). A estos argumentos es posible añadir algunos otros. Entre éstos podrían mencionarse a grandes rasgos y, dada la escasa información arqueológica con la que contamos, simplemente con caracter de hipótesis, varios: la constatación de fenómenos estratigráficos significativos como el nivel de incendio (estrato 8, fines del siglo $\mathrm{V}$ a.C.) y el posterior hiato en la secuencia arqueológica de Sisapo a comienzos de la etapa ibérica plena (Fernández Ochoa-Zarzalejos-Hevia-Esteban, 1994, 149-150), periodo conflictivo en todo el ámbito de la cultura ibérica (Blanco, 1986-87); en concreto, y en un área limítrofe con la que analizamos, momento de la posible configuración de la Beturia (Rodríguez Díaz, 1994) y de aparición generalizada de nuevas etnias en el panorama protohistórico peninsular (Ruiz RodríguezMolinos, 1993, 240-257); o, en relación con lo anterior y con el hecho de una nueva situación en el ámbito ibérico, el surgimiento generalizado de nuevos asentamientos en el área de Valdepeñas en este mismo momento, entre los que destaca un centro principal entre los oppida oretanos como es el propio Cerro Domínguez, Oreto. El inicio del desarrollo histórico del pueblo oretano no puede sin embargo establecerse aún con toda seguridad en este momento, y el vacío arqueológico existente en el área de Valdepeñas desde finales del siglo III hasta prácticamente comienzos del siglo I a.C., sólo subsanado por unos pocos documentos materiales (Mena, 1988; Arévalo-Zarzalejos, 1996), impide el conocimiento adecuado de la evolución cultural de sus gentes en los momentos próximos a la implantación romana y, por tanto, a los comienzos de la información escrita acerca de los pueblos prerromanos de la Península Ibérica.

\section{BIBLIOGRAFÍA}

Alañón Flox, L., 1988: "Prehistoria y Arqueología de San Carlos del Valle (Ciudad Real)". I Congreso de Historia de Castilla-La Mancha, Ciudad Real 1985. III. Pueblos y culturas prehistóricas y protohistóricas (1), Ciudad Real, 139-146.

Almagro Gorbea, M., 1976-78: "La iberización de las zonas orientales de la Meseta". Ampurias 38-40, Simposi internacional: Els origens del món iberic, (Barcelona-Empuries 1977), Barcelona, 93-156

Álvarez Ossorio, F., 1945: "El tesoro ibérico de plata procedente de Torre de Juan Abad (Ciudad Real)", AEA 18, Madrid, 205-211.

Aranegui Gascó, C., 1974: "Consideraciones sobre la cerámica con decoración pintada polícroma en el País Valenciano". Miscelánea Arqueológica XXV, tomo I, Ani- versario de los cursos internacionales de Prehistoria y Arqueología en Ampurias (1947-1971), Barcelona, 87-99.

Aranegui Gascó, C.; Martí, M. A., 1995: "Cerámicas procedentes de un alfar ibérico localizado en el Pla de Piquer (Alfara d'Algina), cerca de Sagunt (Valencia)", Saguntum Homenatje al Professor. Dr. Miquel Tarradell i Mateu, Valencia, 131-149.

Arévalo, A.; Zarzalejos, M., 1996: "Apuntes para las claves interpretativas de la Sisapo republicana: testimonios materiales". XXIII CNA, II, (Elche 1995), Alicante, 161-171.

Balmaseda, J.; Valiente, S, 1979: "Excavaciones en El Cerrón (Illescas, Toledo)". NAHisp 7 Madrid, 153210.

Blanco Frejeiro, A., 1986-87: "Destrucciones antiguas en el mundo ibérico y mediterráneo occidental". CuPAUAM 11-12, vol. II, Homenaje a G. Nieto, Madrid, 3-8.

BLÁNQUEZ PÉREZ, J., 1990: La formación del mundo ibérico en el sureste de la Meseta, Albacete.

BlÁnquez Pérez, J.; RoldÁn, L., 1995: "Catálogo de piezas", El Mundo Ibérico: una nueva imagen en los albores del año 2000, Toledo, 33-63.

Blasco Bosqued, M. C., 1992: "Etnogénesis de la Meseta Sur", Complutum 2-3, Paleoetnología de la Pénínsula Ibérica (Almagro Gorbea y Ruiz Zapatero, editores), Madrid, 281-297.

Blasco Bosqued, M. C.; Alonso Sánchez, M. A., 1983: "Aproximación al estudio de la Edad del Hierro en la provincia de Madrid". Homenaje al Prof. M. Almagro Basch II, Madrid, 119-132.

BlázQuez Martínez, J. M., 1975: Castulo I, Anuario Arqueológico Hispano 8, Madrid.

Blázquez Martínez, J. M.; García Gelabert, M. P., 1992: "Relaciones entre la Meseta y Oretania", Complutum 2-3, Paleoetnología de la Península Ibérica (Almagro Gorbea y Ruiz Zapatero, editores), Madrid, 45-55.

BlázQuez Martínez, J. M.; Contreras, R.; Urruela, J. J., 1984: Castulo IV, Exc. Arq. Esp. 131, Madrid.

Blázquez Martínez, J, M.; García Gelabert, M. P.; LÓpez Pardo, F., 1985: Castulo V, Exc. Arq. Esp. 140, Madrid.

Broncano, S.; Blánquez Pérez, J., 1985: El Amarejo (Bonete, Albacete), Exc. Arq. Esp. 139, Madrid.

Caballero Klink, A.; Mena Muñoz, P., 1987: "Los exvotos ibéricos del Oppidum de Alarcos", XVIII CNA, (Canarias 1985), Zaragoza, 615-633.

Cabrera Bonet, P., 1987: "Consideraciones en torno a la cerámica ática de fines del siglo $\mathrm{V}$ en Extremadura", Oretum III, Ciudad Real, 215-221.

Cabrera Bonet, P.; Sánchez, C., 1994: "Importaciones griegas en el sur de la Meseta", Huelva Arqueológica XIII, I, Iberos y griegos: lecturas desde la diversidad, 
(Simposio internacional, Ampurias 1991, P. Cabrera, R. Olmos y E. Sanmart, coords.), Huelva, 355-376.

Carrasco Serrano, G., 1988: "Fuentes antiguas para el estudio de la Oretania". I Congreso de Historia de Castilla-La Mancha, Ciudad Real 1985. IV. Romanos y Visigodos: hegemonía cultural y cambios sociales, Ciudad Real, 21-23.

Carrobles Santos, J., Ruiz Zapatero, G., 1990: "La necrópolis de la Edad del Hierro de Palomar del Pintado (Villafranca de los Caballeros, Toledo)". Actas del Primer Congreso de Arqueología de la Provincia de Toledo, Toledo, 227-258.

Domínguez Monedero, A., 1988: "Algunas observaciones en torno al "comercio continental griego" en la Meseta Meridional". I Congreso de Historia de Castilla-La Mancha, Ciudad Real 1985. III. Pueblos y culturas prehistóricas y protohistóricas (2), Ciudad Real, 327-334.

Esteban Borrajo, G., 1998: Cerámicas a torno pintadas orientalizantes, ibéricas e iberorromanas de Sisapo, Madrid.

Esteban Borrajo, G., (e.p).: Cerámicas a mano pintadas de Sisapo (La Bienvenida, Almodóvar del Campo, Ciudad Real), Madrid.

esteban Borrajo, G.; Hevia Gómez, P., 1996: "Algunos datos para la caracterización del fenómeno ibérico en la provincia de Ciudad Real", XXIII CNA, I, (Elche 1995), Alicante, 537-544.

Fernández Martínez, V. M.; Hornero, E.; Pérez MugA, J. A., 1994: "El poblado ibérico del "Cerro de las Nieves" (Pedro Muñoz). Excavaciones 19841985", Jornadas de Arqueología de Ciudad Real en la Universidad Autónoma de Madrid, Madrid, 111-124.

Fernández OchoA, C.; CAballero Klink, A., 1986: "La época romana", Historia de la Provincia de Ciudad Real, Ciudad Real, 35-64.

Fernández Ochoa, C.; Caballero Klink, A.;Morano, C., 1982-83: "Nuevo documento epigráfico para la localización de Sisapo". CuPAUAM910, Madrid, 211-220.

Fernández Ochoa, C.; Zarzalejos Prieto, M.; Hevia Gómez, P.; Esteban Borrajo, G., 1994: Sisapo I. Excavaciones arqueológicas en La Bienvenida, Almodóvar del Campo, Ciudad Real, Patrimonio HistóricoArqueológico de Castilla-La Mancha 10, Toledo.

FERnÁNDEZ RodríGuez, M., 1987: La cerámica de barniz rojo del Cerro de Alarcos, Ciudad Real, Ciudad Real.

Fernández Rodríguez, M.; Fonseca Ferrandis, R., 1985: "Materiales ibéricos de la motilla de Los Palacios (Ciudad Real)", Oretum I, Ciudad Real, 257-275.

Fernández Rodríguez M.; Juan García, A.; Caballero KlinK, A., 1993: "Alarcos. El cerro sagrado de la Oretania", Revista de Arqueología 152, Madrid, 36-43.

García Gelabert, M. P.; BlázQuez Martínez, J. M., 1988: Cástulo, Jaén, Excavaciones en la necrópolis ibéri- ca del Estacar de Robarinas (s. IV a.C.), B.A.R. International Series 425, Oxford.

Gil FarRÉs, O., 1952: "Hallazgo cerámico en Alarcos". II CNA, (Madrid 1951), Zaragoza, 397-400.

González Conde Puente, M. P., 1992: "Los pueblos perromanos de la Meseta Sur", Complutum 2-3, Paleoetnología de la Península Ibérica (Almagro Gorbea y Ruiz Zapatero, editores) Madrid, 299-309.

Juan García, A.; Fernández Rodríguez, M.; Caballero Klink, A., 1994: "El yacimiento íberomedieval de Alarcos". Jornadas de Arqueología de Ciudad Real en la Universidad Autónoma de Madrid, Madrid, 143-165.

LÓpez Domech, R., 1996: La región oretana, Anejos de Antigüedad y Cristianismo III, Murcia.

LÓPEz Rozas, J., 1987: "El poblamiento ibérico en la Meseta Sur". I Jornadas sobre el mundo ibérico, (Jaén 1985), Jaén, 335-347.

MaluQuer de Motes, J., 1985: "Comercio continental focense en la Extremadura Central", Ceramiques gregues $i$ helenistiques a la Peninsula Ibérica, Monografies Emporitanes VII, (Ampurias 1983), Barcelona, 19-25.

Maluquer de Motes, J.; Picazo, M.; Rincón, M. A., 1973: La necrópolis ibérica de la Bobadilla, Jaén, Programa de investigaciones protohistóricas I, Barcelona.

Mata Parreño, C., 1985: "Algunas cerámicas ibéricas con decoración impresa en la Provincia de Valencia". Saguntum 19, Valencia, 153-178.

Mena MuÑoz, P., 1984: Catálogo de cerámicas de necrópolis de la Edad del Hierro del Museo de Cuenca, Boletín del Museo Provincial de Cuenca I, Cuenca.

Mena MuÑoz, P., 1988: "La época republicana en CastillaLa Mancha: inicios de la romanización (siglo III-I a.C.)", I Congreso de Historia de Castilla-La Mancha, Ciudad Real 1985. IV. Romanos y visigodos: hegemonía cultural y cambios sociales, Ciudad Real, 25-51.

Mena Muñoz, P.; Ruiz Prieto, A., 1985: "Una nueva muestra de escultura ibérica en la Provincia de Ciudad Real. El toro de Alcubillas", Oretum I, Ciudad Real, 251-256.

Molina, F.; Carrión, F.; Blanco, I.; Contreras, F.; LÓPEZ, J., 1983: "La motilla de Las Cañas (Daimiel, Ciudad Real). Campaña de 1983". Cuadernos de Prehistoria de la Universidad de Granada 8, Granada, 301-316.

Nieto Gallo, G.; Sánchez Meseguer, J. L.; Poyato Holgado, C., 1980: Oreto I, Exc. Arq. Esp. 114, Madrid.

Oliver Foix, A., 1982-83: "Nuevas aportaciones para el estudio de la cerámica polícroma ibérica en el País Valenciano", Cuadernos de Prehistoria y Arqueología Castellonenses 9, Castellón, 193-203.

Patiño Gómez, M. J.; González Garrido, M. C., 1985: "Torque y brazalete de la finca "Las Navas", 
Almadenejos (Ciudad Real)", Oretum I, Ciudad Real, 241-249.

Pereira Sieso, J., 1979: "La cerámica ibérica procedente de Toya (Peal de Becerro, Jaén) en el Museo Arqueológico Nacional", TP 6, Madrid, 287-347.

PÉREZ, C. J., 1987: "Materiales arqueológicos del bronce, ibéricos y romanos de Almedina (Ciudad Real). Resultados de unas prospecciones" Oretum III, Ciudad Real. 197-213.

Pérez Avilés, J. J., 1985: "Estudio arqueológico del Campo de Montiel" Oretum I, Ciudad Real, 175-237.

Prada JunQuera, M., 1977: "Las esfinges oretanas del Oppidum de Alarcos", XIV CNA, (Vitoria 1975), Zaragoza, 695-704.

Rodríguez DíAz, A., 1989: "La Segunda Edad del Hierro en la baja Extremadura: Problemática y perspectiva en torno al po-blamiento", Saguntum 22, Valencia, 165-221.

Rodríguez DíAz, A., 1994: "Algunas reflexiones sobre el fin de Tartessos en la cuenca media del Guadiana: la crisis del cuatrocientos y el desarrollo de la Beturia", CuPAUAM 21, Madrid, 9-34.

Ruiz Rodríguez, A., 1992: "Etnogénesis de las poblaciones prerromanas de Andalucía Oriental", Complutum 2-3, Paleoetnología de la Península Ibérica (Almagro Gorbea y Ruiz Zapatero, editores) Madrid, 101-118.

Ruiz Rodríguez, A., 1997: "Desarrollo y consolidación de la ideología aristocrática entre los iberos del sur", Iconografía ibérica, iconografía itálica: propuestas de interpretación y lectura, (Coloquio Internacional, Roma 11-13 Noviembre 1993, R. Olmos y J. A. Santos eds. científicos), Universidad Autónoma de Madrid, Serie Varia 3, Madrid, 61-71.

Ruiz Rodríguez, A.; Molinos, M., 1993: Los iberos. Análisis arqueológico de un proceso histórico, Barcelona.

Ruiz Rodríguez, A.; Nocete Calvo, F., 1981: "Un modelo sincrónico para el análisis de la producción de cerámica ibérica estampillada del Alto Guadal- quivir". Cuadernos de Prehistoria de la Universidad de Granada 6, Granada, 355-385.

Ruiz Rodríguez, A.; Molinos, M.; Hornos, F.; Choclán, C., 1987: "El poblamiento ibérico en el Alto Guadalquivir", I Jornadas sobre el mundo ibérico, (Jaén 1985), Jaén, 239-256.

Valiente CÁnovas, S., 1987: "La cultura de la II Edad del Hierro". Catálogo de la Exposición 130 años de Arqueología madrileña, (Real Academia de Bellas Artes de San Fernando, Febrero-Marzo 1987), Madrid, 120-134.

VAliente CÁnovas, S., 1994: Excavaciones arqueológicas en El Cerrón, Illescas (Toledo), Patrimonio HistóricoArqueológico de Castilla-La Mancha 11, Toledo.

Valiente Cánovas, S.; Balmaseda Muncharaz, L. J., 1983: "Hacia una delimitación de la Carpetania en la Edad del Hierro II", Homenaje al Prof. M. Almagro Basch, II, Madrid, 135-142.

Vall, M. A.; Pla Ballester, E., 1969: "Cerámicas polícromas en los poblados ibéricos valencianos", $\mathrm{X}$ CNA, (Mahón 1967), Zaragoza, 288-305.

Vélez Rivas, J.; Pérez Avilés, J. J., 1987: "El yacimiento protohistórico del Cerro de Las Cabezas (Valdepeñas, Ciudad Real)", Oretum III, Ciudad Real, 167-196.

Vigil de la Huerta, R.; García Giménez, R., 1995: "Análisis de cerámicas a torno pintadas de La Bienvenida", en Cerámicas a torno pintadas orientalizantes, ibéricas e iberorromanas de Sisapo, (Esteban, 1998), Madrid, 187-198.

Zarzalejos Prieto, M., 1994: Arqueología de la regiónn sisaponense. Aproximación a la evolución histórica del área SW. de la provincia de Ciudad Real (fines s. VIII a.C.-II d.C.), Tésis doctoral en microfichas, Universidad Autónoma de Madrid, Madrid.

Zarzalejos Prieto, M.; Fernández Ochoa, C.; Hevia Gómez, P.; Esteban Borrajo, G., 1995: "Cerámicas griegas de Sisapo (La Bienvenida, Ciudad Real)", XXII CNA, (Vigo 1993), Vigo, 183-189. 